\title{
Hemorheological parameters in Monoclonal Gammopathy of Undetermined Significance (MGUS)
}

G. Caimi ${ }^{\mathrm{a}, *}$, E. Hopps ${ }^{\mathrm{a}}$, M. Carlisi ${ }^{\mathrm{a}}$, M. Montana ${ }^{\mathrm{a}}$, E. Gallă $\grave{a}^{\mathrm{a}}$, R. Lo Presti ${ }^{\mathrm{b}}$ and S. Siragusa ${ }^{\mathrm{a}}$ ${ }^{a}$ Dipartimento Biomedico di Medicina Interna e Specialistica, Università di Palermo, Palermo, Italy ${ }^{\mathrm{b}}$ Dipartimento di Scienze Psicologiche, Pedagogiche e della Formazione, Università di Palermo, Palermo, Italy

\begin{abstract}
There is scarcity of information about the hemorheological pattern in subjects with Monoclonal Gammopathy of Undetermined Significance (MGUS). This preliminary research is focused on the behaviour of whole-blood and plasma viscosity, haematocrit and erythrocyte deformability in the above clinical condition. We enrolled 21 MGUS subjects (10 women and 11 men; mean age $66.4 \pm 11.6$ years). In fasting venous blood we examined whole-blood and plasma viscosity at high and low shear rates, haematocrit, the ratios between whole-blood viscosity (at high and low shear rate) and haematocrit $x$ 100 , the ratio between plasma viscosity at low and high shear rate, and the erythrocyte deformability expressed as elongation index. By comparing normal controls to MGUS subjects a significant increase in whole-blood viscosity at high shear rate and in plasma viscosity at low shear rate were observed. In MGUS subjects the ratios between the high and low shear rate blood viscosity and haematocrit $\times 100$, as well as the ratio between the low and high shear rate plasma viscosity were significantly higher. In MGUS subjects a marked decrease in erythrocyte deformability was also observed. The alteration of the hemorheological profile found in these subjects might be involved in the pathogenesis of thromboembolic events, which occur with a high frequency in MGUS.
\end{abstract}

Keywords: Paraproteinemia, blood viscosity, plasma viscosity, erythrocyte deformability

\section{Introduction}

Monoclonal Gammopathy of Undetermined Significance (MGUS) is defined as the presence of a monoclonal protein (M-protein) at a serum concentration $<30 \mathrm{~g} / \mathrm{L}$, clonal plasma cells in bone marrow $<10 \%$, no end-organ damage and no evidence of B-cell lymphoma or other disease known to produce an M-protein. This process is not considered neoplastic since it does not always progress to overt malignancy.

IgG-MGUS and IgA-MGUS are associated with the presence of clonal plasma cells, and may progress to multiple myeloma (MM), while the presence of a small IgM paraprotein (IgM-MGUS) is associated with a clone of lymphoplasmacytic cells that may progress to a lymphoplasmacytic lymphoma, and/or Waldenstrom's macroglobulinemia (WM).

MGUS is found in approximately $3 \%$ of subjects aged over 50 and in more than $5 \%$ of individuals older than 70 years, and is more common in men than women $(\sim 1.5: 1)$. No specific cause of MGUS has been identified. It may be associated with connective tissue diseases, peripheral neuropathies,

*Corresponding author: Gregorio Caimi, Dipartimento Biomedico di Medicina Interna e Specialistica, Università degli Studi di Palermo, Via del vespro 129, 90100 Palermo, Italy. Tel.: +39 091 6554406; Fax: +39 091 6554535; E-mail: gregorio.caimi@unipa.it. 
dermatological, endocrine and liver diseases. Obesity and personal history of autoimmune diseases, inflammatory conditions and infections are associated with increased risk of MGUS. Furthermore, occupational studies have demonstrated that exposure to radiation or pesticide seems to be associated with the development of MGUS [4, 41].

Subjects exhibit no symptoms or physical evidences related to MGUS. The typical laboratory and radiographic abnormalities associated with MM are absent. The M-protein is usually discovered unexpectedly on serum protein electrophoresis. Approximately $70 \%$ are $\operatorname{IgG}, 15 \% \operatorname{IgM}, 12 \% \operatorname{IgA}$ and $3 \%$ are biclonal. Up to $20 \%$ of MGUS may consist only of an Ig light chain (LC-MGUS) that must be detected with the serum free light chain assay. A reduction of uninvolved Ig is observed in 30-40\% of MGUS subjects and monoclonal light chain in urine is near to a third; abnormal karyotypes are rarely detected in MGUS.

The clinical course in most MGUS patients is stable, with no increase in M-protein or other evidence of progression. However, there may be an escalation to an overt MM, amyloidosis (in non-IgM MGUS), WM or other lymphoproliferative disorders (in IgM MGUS). The risk is about $1 \%$ per year and persists even after 30 years; thus, MGUS should be considered a pre-neoplastic condition [23, 27, 39, 44].

There are certain characteristics useful to predict the escalation from MGUS to a symptomatic disease: the size of the MGUS clone as determined by bone marrow plasma cell percentage, the M-protein level, the heavy-chain isotype ( $\operatorname{IgA} / \operatorname{IgM}>\operatorname{IgG})$, the light-chain production as determined by abnormal serum free light chain ratio, the presence of Bence Jones proteinuria or the detection of circulating plasma cells or clonal B cells. Furthermore, suppression of non-clonal bone marrow plasma cells, detected by multiparameter flow cytometric analysis, has been identified as a risk factor for the escalation.

Based on available clinical markers, the Mayo Clinic and the Spanish study group established predictive risk models for the escalation from MGUS to MM. The Mayo Clinic model emphasizes the clonal plasma cell burden with monoclonal protein values and skewed free light-chain ratios, whereas the Spanish study group uses multiparametric flow cytometry techniques to identify aberrant plasma cell populations [19].

Outside of clinical trials, there are no current standardized treatment options for MGUS, although since 2010, the International Myeloma Working Group guidelines have suggested risk-stratifying of all subjects with MGUS and differential monitoring of subjects based on their risk category as well as on their life expectancy depending on age and presence of comorbidities [22].

Considering the above data, and according to Castillo [6], MGUS may be considered a benign plasma cell disorder characterized by the presence of monoclonal paraprotein in serum or urine. However, the presence of the paraprotein may alter the whole-blood viscosity (WBV), as it is the case for MM and WM [11, 21, 24, 25, 29, 35, 36]. The alteration of WBV plays a more prominent role in microcirculation than in large vessel hemodynamics. Physiologically, blood flow is influenced by blood velocity, vessel diameter and WBV; the latter is determined by haematocrit (Ht), plasma viscosity (PV), red cell aggregation and deformability. WBV varies in relation with shear rate and several clinical and experimental data have clearly demonstrated that red cell deformability and PV are the main determinants of flow at high shear rate, while red cell aggregation rises to prominence during flow at low shear rate.

To date, only two papers examined the behaviour of the hemorheological pattern in subjects with MGUS. A study [40] was carried out on a group of 87 patients who were affected by plasma cell dyscrasias (PCD), including MM $(n=52)$, MGUS $(n=30)$, WM $(n=5)$. The study examined WBV and PV: $71 \%$ of the PCD patients showed PV above the reference limit, and $40 \%$ had WBV above the reference limit. Another research paper [7] focused on the erythrocyte aggregation, red cell deformability and microcirculation (Periflux tests) in a group of 8 patients with active MM, 9 MM patients in 
remission and 7 MGUS subjects. In this study MGUS subjects differed from the two groups of MM patients in erythrocyte aggregation and microcirculatory tests but not in erythrocyte deformability.

The aim of this preliminary study was the evaluation of WBV, PV, Ht and erythrocyte deformability in a group of MGUS subjects.

\section{Subjects}

A group of 21 subjects (10 women and 11 men; mean age $66.4 \pm 11.6$ years) with MGUS were examined. The M-protein was IgG in 18 subjects and IgM in 2; in a subject both monoclonal IgG and $\operatorname{IgA}$ were observed. The time interval from the first detection of the M-protein was $41.3 \pm 50.2$ months. The principal laboratory findings in these MGUS subjects were: $\mathrm{Hb}(\mathrm{g} / \mathrm{dl}) 12.94 \pm 1.80$ (range 10.1-17.1), Red-cell Distribution Width (RDW - \%) 13.78 \pm 1.26 (range 12.4-17.1), creatinine (mg/dl) $0.95 \pm 0.23$ (range 0.7-1.4), beta2-microglobulin ( $\mu \mathrm{g} / \mathrm{ml}$ ) $2.954 \pm 1.311$ (range 0.75-5.68), calcium (mg/dl) $9.409 \pm 0.425$ (range 8.8-10.1), albumin (g/L) $41.53 \pm 3.53$ (range 36.8-48.2), IgG (mg/dl) $1656 \pm 737.4$ (range 771-2872), IgA (mg/dl) $201 \pm 205.3$ (range 40-805), IgM (mg/dl) $333.7 \pm 743.2$ (range 21.6-2668), fibrinogen (mg/dl) 267.4 \pm 36.12 (range 215-340), M-protein (g/dl) $0.922 \pm 0.439$ (range 0.150-1.800). The control group included 21 subjects ( 8 women and 13 men; age range 23-63 years), whose health was assessed through clinical history, physical examination, electrocardiography, routine blood and urine analyses.

\section{Methods}

Venous blood samples were collected in the morning by venous puncture from the antecubital vein of fasting subjects and immediately transferred to anticoagulated glass tubes for the evaluation of the following parameters:

- WBV at the shear rate of $450 \mathrm{sec}^{-1}$, by using the cone-on-plate viscometer Well-Brookfield $1 / 2$ LVT (Middleboro, MA, USA), at $37^{\circ} \mathrm{C}$;

- WBV at the shear rate of $0.51 \mathrm{sec}^{-1}$ employing the viscometer Contraves LS30 (proRheo GmbH, Althengstett,Germany), at $37^{\circ} \mathrm{C}$;

- PV at the shear rate of $450 \mathrm{sec}^{-1}$, by using the cone-on-plate viscosimeter Wells-Brookfield 1/2 LVT, at $37^{\circ} \mathrm{C}$;

- PV at the shear rate of $0.51 \mathrm{sec}^{-1}$ employing the viscometer Contraves LS30, at $37^{\circ} \mathrm{C}$;

- Ht, obtained by using a micromethod;

- WBV at $450 \mathrm{sec}^{-1} / \mathrm{Ht} \times 100$;

- WBV at $0.51 \mathrm{sec}^{-1} / \mathrm{Ht} \times 100$;

- PV at $0.51 \mathrm{sec}^{-1} / \mathrm{PV}$ at $450 \mathrm{sec}^{-1}$;

- Erythrocyte deformability: to evaluate this parameter, a sample of $30 \mu \mathrm{l}$ of anticoagulated blood was mixed with $2 \mathrm{ml}$ of dextran solution with a viscosity of $24 \mathrm{mPa} \cdot \mathrm{s}$. The measurement was obtained by using the diffractometer Rheodyn SSD of Myrenne, which measures the diffraction pattern of a laser beam passing through erythrocytes suspended in a viscous medium and deformed by a force with defined shear stress. The shear stress employed was 6, 12, 30 and $60 \mathrm{~Pa}$. The erythrocyte deformation was expressed as elongation index $(E I)=(1-w / 1+w) \times 100$, where $1=$ length and $\mathrm{w}=$ width of the erythrocytes. 


\section{Statistical analysis}

Data were expressed as means \pm S.D. The Student's $t$ test for unpaired data was used to compare normal controls to MGUS subjects. The correlation between WBV and Ht, WBV and PV, WBV and EI in normal controls and MGUS subjects, and between PV and the concentrations of fibrinogen, Ig and M-protein in MGUS subjects was examined using the linear regression.

\section{Results}

By comparing normal controls to MGUS subjects, a significant increase in WBV at high shear rate and a marked increase in PV at low shear rate were found (Table 1). Subsequently we studied the correlations between WBV (at high and low shear rates) and Ht in normal controls and in MGUS subjects, which resulted statistically significant (Fig. 1). PV (at high and low shear rate) was not correlated with the concentrations of Ig, M-protein and fibrinogen in MGUS subjects (data not shown). We also evaluated the correlations between high shear rate WBV and high shear rate PV, and between low shear rate WBV and low shear rate PV, both in normal controls and MGUS subjects (Fig. 2). A significant correlation was found, in both groups, only between high shear rate WBV and high shear rate $\mathrm{PV}$. The ratios between high and low shear rate $\mathrm{WBV} / \mathrm{Ht} \times 100$ and the ratio between $\mathrm{PV}$ at low and high shear rate were considered (Table 2). All the three ratios were significantly higher in MGUS subjects in comparison with normal controls. The erythrocyte deformability, expressed as EI, was markedly decreased in MGUS subjects (Table 3). WBV at high and low shear rates was not correlated with EI (data not shown).

\section{Discussion}

Our results show an increase of high shear rate WBV and low shear rate PV in MGUS subjects. These findings are different from those observed in MM by our research group (data submitted); in MM patients, in fact, a marked decrease in Ht prevented WBV from being elevated. In MGUS subjects we observed a significant increase in PV at low shear rate, as well as a higher low shear rate PV/high shear rate PV ratio. Since plasma is generally considered a newtonian fluid, its viscosity should not vary at different shear rates. However, the use of rotational viscometers elicits a different behaviour of PV at high and low shear rate respectively; this effect was probably amplified in our study by the use of two different devices. Taking into account the technical conditions in which we performed the measurement, a different behaviour was evident between MGUS patients and control subjects, and the properties of the M-protein are likely to be responsible for that.

Table 1

Means \pm S.D. of the hemorheological determinants in control subjects and MGUS patients

\begin{tabular}{|c|c|c|}
\hline & Control subjects & MGUS patients \\
\hline WBV $450 \mathrm{sec}^{-1}(\mathrm{mPa} \cdot \mathrm{s})$ & $2.934 \pm 0.393$ & $3.353 \pm 0.504^{* *}$ \\
\hline WBV $0.51 \mathrm{sec}^{-1}(\mathrm{mPa} \cdot \mathrm{s})$ & $24.18 \pm 4.40$ & $26.80 \pm 6.32$ \\
\hline $\mathrm{PV} 450 \mathrm{sec}^{-1}(\mathrm{mPa} \cdot \mathrm{s})$ & $1.210 \pm 0.065$ & $1.196 \pm 0.140$ \\
\hline PV $0.51 \mathrm{sec}^{-1}(\mathrm{mPa} \cdot \mathrm{s})$ & $2.657 \pm 0.659$ & $4.429 \pm 0.769^{* * *}$ \\
\hline $\mathrm{Ht}(\%)$ & $41.67 \pm 3.51$ & $39.24 \pm 4.56$ \\
\hline
\end{tabular}

${ }^{* *} p<0.01{ }^{* * *} p<0.001$ vs Control Subjects (Student's $t$ test for unpaired data). WBV $=$ WholeBlood Viscosity; PV = Plasma Viscosity; $\mathrm{Ht}=$ Haematocrit $\mathrm{mPa}=$ milliPascal. 
(A)

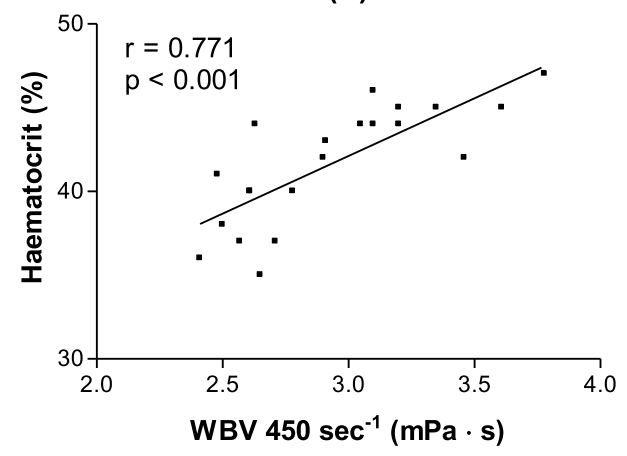

(B)

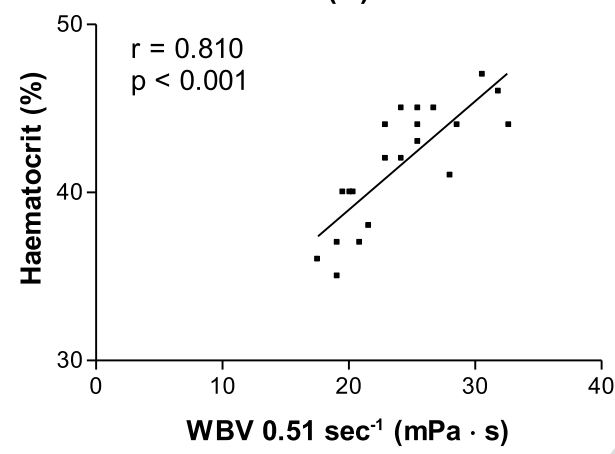

(C)

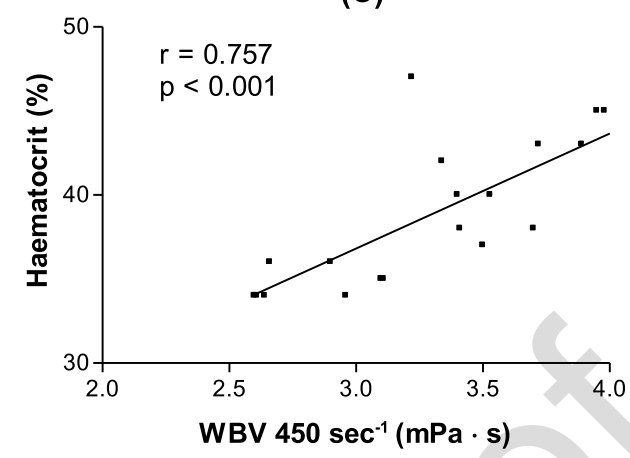

(D)

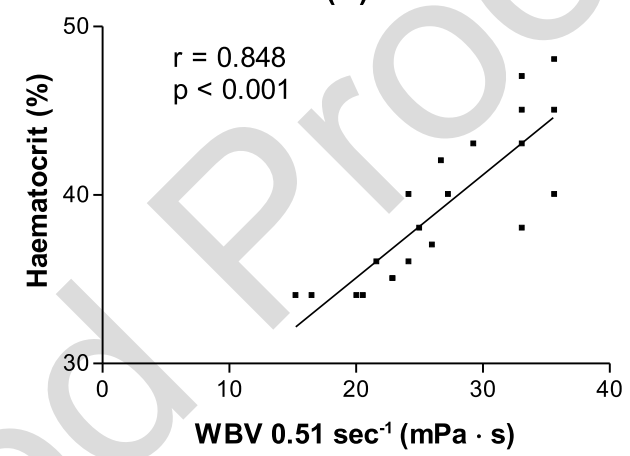

Fig. 1. Correlations between whole-blood viscosity (WBV) and haematocrit in control subjects (A-B) and in MGUS patients (C-D).

PV seems to be an independent risk factor especially for cardiovascular diseases [5, 15, 18, 34], and in MGUS the risk of venous thromboembolic events is increased [14, 20, 37, 38, 45]. Some studies focused on the coagulation profile present in this clinical condition $[9,10]$, but the possibility that the alteration of the hemorheological profile contributes to the pathogenesis of venous thromboembolic events in MGUS subjects cannot be ruled out. In fact, there has been much research on the role of hemorheological alterations in arterial and venous thrombosis [2, 8, 26, 42]. An unexpected finding of this preliminary study was the behaviour of the erythrocyte deformability in the MGUS subjects. The factors able to reduce this hemorheological parameter are an alteration of the surface/volume ratio, an increased cytosolic viscosity and an impairment of the red cell membrane dynamic properties, referable especially to an alteration of membrane lipids and proteins. In MGUS subjects no abnormalities in the erythrocyte membrane lipid profile, plasma lipid composition or fatty acid metabolism are known, whereas such alterations have been observed in patients with MM $[16,17,43]$.

The only abnormality of the erythrocyte membrane noted in MGUS regards the membrane proteins and consists in the presence of a paroxysmal nocturnal hemoglobinuria-like (PNH-like) defect in some MGUS subjects [12,33]. This defect is characterized by an altered synthesis of glycosilphosphatidylinositol, which is essential for the binding of some surface proteins, such as CD55 and CD59, able to protect the red blood cells from intravascular lysis. To date PNH-like clones have been observed in several haematological disorders such as aplastic anaemia, myelodysplastic syndromes and myeloproliferative disorders [30], but also in lymphoproliferative syndrome [31] and in acute leukemia [32]. In the last years, the PNH-like defect was observed in a large group of patients with rheumatic diseases [3]. It was also demonstrated that in endothelial cells incubated with high concentration of glucose the 
(A)

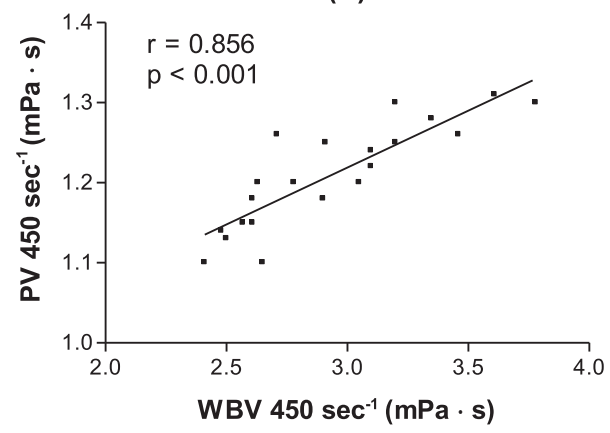

(B)

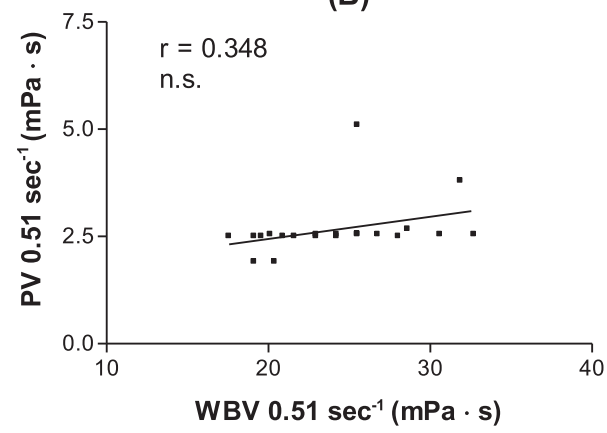

(C)

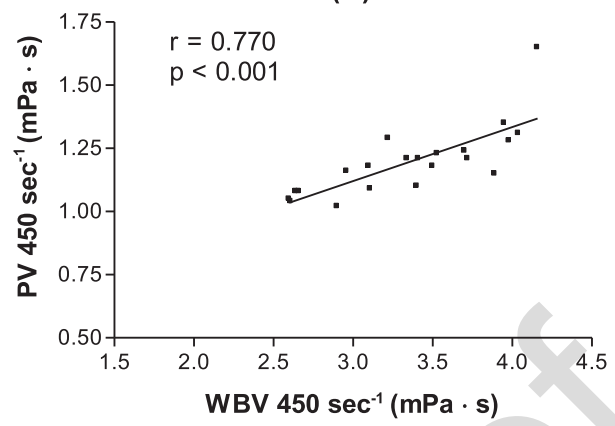

(D)

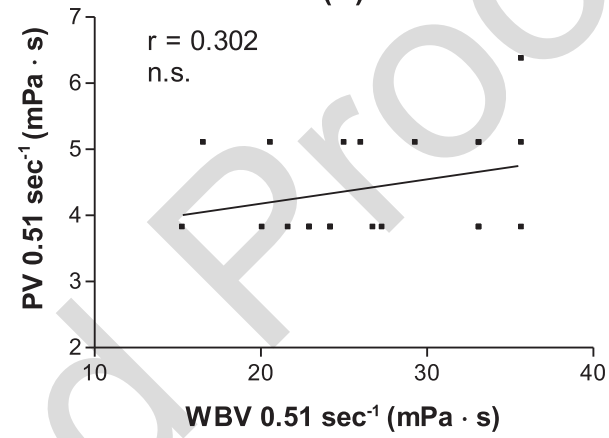

Fig. 2. Correlations between whole-blood viscosity (WBV) and plasma viscosity (PV) in control subjects (A-B) and in MGUS patients (C-D).

Table 2

Means \pm S.D. of the hemorheological indexes in control subjects and MGUS patients

\begin{tabular}{lcc}
\hline & Control subjects & MGUS patients \\
\hline WBV 450/Ht× 100 & $7.031 \pm 0.598$ & $8.545 \pm 0.825^{* * *}$ \\
WBV 0.51/Ht $\times 100$ & $57.74 \pm 7.07$ & $67.65 \pm 10.72^{* *}$ \\
PV 0.51/PV 450 & $2.20 \pm 0.53$ & $3.71 \pm 0.55^{* * *}$
\end{tabular}

${ }^{* *} p<0.01{ }^{* * *} p<0.001$ vs Control Subjects (Student's $t$ test for unpaired data). $\mathrm{WBV}=$ Whole-Blood Viscosity; PV = Plasma Viscosity; Ht = Haematocrit.

Table 3

Means \pm S.D. of erythrocyte deformability in control subjects and MGUS patients

\begin{tabular}{lcc}
\hline & Control subjects & MGUS patients \\
\hline EI 60 & $45.13 \pm 2.67$ & $40.24 \pm 2.93^{* * *}$ \\
EI 30 & $41.84 \pm 2.42$ & $34.34 \pm 3.11^{* * *}$ \\
EI 12 & $33.37 \pm 2.35$ & $23.47 \pm 3.27^{* * *}$ \\
EI 6 & $25.05 \pm 2.39$ & $14.46 \pm 3.19^{* * *}$ \\
\hline
\end{tabular}

${ }^{* * *} p<0.001$ vs Control Subjects (Student's $t$ test for unpaired data). EI = Elongation Index. 
expression of CD55 and CD59 decreased, and could be normalized by co-incubation with the calcium channel-blocking agent verapamil [1].

There are some differences between IgM-MGUS and non-IgM-MGUS [13, 28], in particular in the risk of progression and transformation, but in our study the number of MGUS subjects was too small to allow a comparison between the hemorheological profile of IgM-MGUS and that of non-IgM-MGUS.

In conclusion, even though MGUS is an asymptomatic, premalignant disorder, it is associated with hemorheological abnormalities including not only the expected increase in PV but also a decrease in erythrocyte deformability; both alterations can be involved in the thromboembolic manifestations of the condition.

This research complies with the requirement for ethical publication in Clinical Hemorheology and Microcirculation as published in Clin Hemorheol Microcirc. 2010;44(1):1-2.

\section{References}

[1] Accardo-Palumbo A, Triolo G, Colonna-Romano G, Potestio M, Ferrante A, Giardina E, Caimi G, Triolo G. Glucoseinduced loss of glycosil-phosphatidylinositol-anchored membrane regulators of complement activation (CD59, CD55) by in vitro cultured human umbelical vein endothelial cells. Diabetologia. 2000;43:1039-47.

[2] Alt S, Banyai S, Banyai M, Koppensteiner R. Blood rheology in deep venous thrombosis-relation to persistent and transient risk factors. Thrombosis Research. 2002;107:101-7.

[3] Asimakopoulos JV, Terpos E, Papageorgiou L, Kampouropoulou O, Christoulas D, Giakomumis A, Samarkos M, Vaiopoulos G, Konstantopoulos K, Angelopoulou MK, Vassilakopoulos TP, Melitis J. The presence of CD55- and/or CD59-deficient erythrocytic populations in patients with rheumatic diseases reflects an immune-mediated bone-marrow derived phenomenon. Med Sci Monit. 2014;20:123-39.

[4] Bida JP, Kyle RA, Therneau TM, Melton J, Plevak MF, Larson DR, Dispenzieri A, Katzmann JA, Rajkumer SV. Disease associations with monoclonal gammopathy of undetermined significance: A population-based study of 17,398 patients. Mayo Clin Proc. 2009;84:685-93.

[5] Caimi G, Lo Presti R, Andolina G, Hopps E. Short-term prognosis of juvenile myocardial infarction: Role of plasma viscosity. Angiology. 2016;67:799-801.

[6] Castillo JJ. Plasma cell disorders. Prim Care. 2016;43:677-91.

[7] Cicco S, Ditonno P, Reale A, Savino S, Castrovilli A, Catacchio I, Ria R, Vacca A. Could multiple myeloma VEGF modify the sistemic microcirculation? Adv Exp Med Biol. 2012;737:155-60.

[8] Coppola A, Tufano A, Di Capua M, Franchin M. Bleeding and thrombosis in multiple myeloma and related plasma cell disorders. Semin Thromb Hemost. 2011;37:929-45.

[9] Crowley MP, Kevane B, O’Shea SI, Quinn S, Egan K, Gilligan OM, Ni Ainle F. Plasma thrombin generation and sensitivity to activated protein $\mathrm{C}$ among patients with myeloma and monoclonal gammopathy of undetermined significance, Clin Appl Thromb Hemost. 2016;22:554-62.

[10] Crowley MP, Quinn S, Coleman E, Eustace JA, Gilligan OM, O'Shea SI. Different coagulation profiles of patients with monoclonal gammopathy of undetermined signficance and multiple myeloma. J Thromb Thrombolysis. 2015;39:245-9.

[11] Dintenfass L, Somer T. On the aggregation of red cells in Waldenstrom's macroglobulinemia and multiple myeloma. Microvas Res. 1975;9:279-86.

[12] Fukumoto JS, Gotlib J. A patient with paroxysmal nocturnal hemoglobnuria, T cell large granular lymphocyte clonal expansion, and monoclonal gammopathy of undetermined significance. Am J Hematol. 2006;81:870-4.

[13] Gobbi P, Baldini L, Broglia C, Goldaniga M, Comelli M, Morel P, Morra E, Cortelazzo S, Bettini R, Merlini G. Prognostic validation of the International Classification of immunoglobulin $\mathrm{M}$ gammopathies: A survival advantage for patients with immunoglobulin M monoclonal gammopathy of undetermined significance? Clin Cancer Res. 2005;11:1786-90.

[14] Gregersen H, Norgaard M, Severinsen MT, Engebjerg MC, Jensen P, Sorensen HT. Monoclonal gammopathy of undetermined significance and risk on venous thromboembolism. Eur J Haematol. 2010;86:129-34.

[15] Grotemeyer KC, Kaiser R, Grotemeyer KH, Husstedt IW. Association of elevated plasma viscosity with small vessel occlusions in ischemic cerebral disease. Thromb Res. 2014;133:96-100.

[16] Jurczyszyn A, Czepiel J, Gdula-Argasińska J, Czapkiewicz A, Biesiada G, Dróżdż M, Perucki W, Castillo JJ. Erythrocyte membrane fatty acids in multiple myeloma patients. Leuk Res. 2014;38:1260-5.

[17] Jurczyszyn A, Czepiel J, Gdula-Argasińska J, Paśko P, Czapkiewicz A, Librowski T, Perucki W, Butrym A, Castillo JJ, Skotnicki AB. Plasma fatty acid profile in multiple myeloma patients. Leuk Res. 2015;39:400-5. 
[18] Kesmarky G, Kenyeres P, Rabai M, Toth K. Plasma viscosity: A forgetten variable. Clin Hemorheol Microcir. 2008;39:243-6.

[19] Korde N, Kristinsson SY, Landgren O. Monoclonal gammopathy of undetermined significance (MGUS) and smoldering multiple myeloma (SMM): Novel biological insights and development of early treatment strategies. Blood. 2011;117:5573-81.

[20] Kristinsson SY, Pfeiffer RM, Bjorkholm M, Goldin LR, Schulman S, Blimark C, Mellqvist U-H, Wahlin A, Turesson I, Landgren O. Arterial and venous thrombosis in monoclonal gammopathy of undetermined significance and multiple myeloma: A population-based study. Blood. 2010;115:4991-8.

[21] Kwaan HC. Hyperviscosity in plasma cell dyscrasias. Clin Hemorheol Microcirc. 2013;55:75-83.

[22] Kyle RA, Durie BG, Rajkumar SV, Landgren O, Blade J, Merlini G, Kröger N, Einsele H, Vesole DH, Dimopoulos M, San Miguel J, Avet-Loiseau H, Hajek R, Chen WM, Anderson KC, Ludwig H, Sonneveld P, Pavlovsky S, Palumbo A, Richardson PG, Barlogie B, Greipp P, Vescio R, Turesson I, Westin J, Boccadoro M. International Myeloma Working Group. Monoclonal gammopathy of undetermined significance (MGUS) and smoldering (asymptomatic) multiple myeloma: IMWG consensus perspectives risk factors for progression and guidelines for monitoring and management. Leukemia. 2010;24:1121-7.

[23] Landgren O, Kyle RA, Pfeiffer RM, Katzmann JA, Caporaso NE, Hayes RB, Dispenzieri A, Kumar S, Clark RJ, Baris D, Hoover R, Rajkumar SV. Monoclonal gammopathy of undetermined signficance (MGUS) consistently precedes multiple myeloma: A prospective study. Blood. 2009;113:5412-7.

[24] Leblond PF. Hemorheology and blood diseases. In: Clinical Hemorheology, Chien S, Dormandy J, Ernst E, Matrai A (1987) by Martinus Nijhoff Publishers, Dordrecht.

[25] Lowe GDO. Rheology of paraproteinemias and leukemias. In: Clinical Blood Rheology, Lowe GDO (1988) by CRC Press, Inc. Vol I.

[26] Lowe GDO, Forbes CD. Rheology of cardiovascular disease. In: Clinical Blood Rheology, Lowe GDO (1988) by CRC Press, Inc. Vol I.

[27] McKenna RW, Kyle RA, Kuehl WM, Grogan TM, Harris NL, Coupland RW. Plasma cell neoplasm (2008), In: Swerdlow SH, Campo E, Harris NL, Jaffe ES, Pileri SA, Stein H, et al. (eds) WHO Classification of Tumours of Haemopoietic and Lymphoid Tissues, IARC, Lyon.

[28] McMaster ML, Landgren O. Prevalence, clinical aspects and natural history of IgM MGUS. Cytometry Part B. 2010;78B(Suppl. 1):S91-7.

[29] Mehta J, Singhal S. Hyperviscosity syndrome in plasma cell dyscrasias. Semin Thromb Hemost. 2003;29:467-1.

[30] Meletis J, Terpos E, Samarkos M, Meletis C, Konstantopoulos K, Komninaka V, Apostolidou E, Benopoulou O, Korovesis K, Mavrogianni D, Variami E, Yataganas X, Loukopoulos D. Detection of CD55 and/or CD59 deficient red cell population in patients with aplastic anaemia, myelodisplastic syndromes and myeloproliferative disorders. Haematologia. 2001;31:7-16.

[31] Meletis J, Terpos E, Samarkos M, Meletis C, Apostolidou E, Komninaka V, Korovesis K, Mavrogianni D, Boutsis D, Variami E, Viniou N, Konstantopoulos K, Loukopoulos D. Detection of CD55 and/or CD59- deficient red cell population in patients with lymphoproliferative syndromes. Hemat J. 2001;2:33-7.

[32] Meletis J, Terpos E, Samarkos M, Meletis C, Apostolidou E, Komninaka V, Anargyrou K, Korovesis K, Mavrogianni D, Variami E, Viniou N, Konstantopoulos K. Red cells with paroxysmal nocturnal hemoglobinuria-phenotype with acute leukaemia. Hematology. 2002;7:69-74.

[33] Meletis J, Terpos E, Samarkos M, Meletis C, Apostolidou E, Komninaka V, Korovesis K, Anargyrou K, Benopoulou O, Mavrogianni D, Variami E, Viniou N, Konstantopoulos K. Detection of CD55- and/or CD59-deficient red cell populations in patients with plasma cell dyscrasias. Int J Hematol. 2002;75(1):40-4.

[34] Patterson CC, Blankenberg S, Ben-Shlomo Y, Heslop L, Bayer A, Lowe G, Zeller T, Gallacher J, Young I, Yarnell J. Which biomarkers are predictive specifically for cardiovascular or for non-cardiovascular in men? Evidence from the Caerphilly Prospective Study(CaPS). Int J Cardiol. 2015;201:113-8.

[35] Preston FE. Circulatory complications of leukaemia and paraproteinemia (1981) In Clinical aspects of blood viscosity and cell deformability. Lowe GDO, Barbenel JC, Forbes CD (eds) Springer Verlag, Berlin and New York.

[36] Reinhart WH, Lutolf O, Nydegger UR, Mahler F, Straub PW. Plasmapheresis for hyperviscosity syndrome in macroglobulinemia Waldenstrom and multiple myeloma: Influence on blood rheology and the microcirculation. J Lab Clin Med. 1992;119:69-76.

[37] Righini M, Boehlen F, Gueddi S, Le Gal G, de Moerloose P. Extensive thromboembolic event as initial presentation of monoclonal gammopathy of undetermined significance. Thromb Haemost. 2006;96:93-4.

[38] Sallah S, Husain A, Wan J, Vos P, Ngujen NP. The risk of venous thromboembolic disease in patients with monoclonal gammopathy of undetermined significance. Ann Onc. 2015;15:1490-4. 
[39] Sigurdardottir EE, Tureson I, Lund SH, Lindqvist EK, Mailankody S, Korde N, Bjorkholm M, Ladgren O, Kristinsson SY. The role of diagnosis and clinical follow-up of monoclonal gammopathy of undetermined significance on survival in multiple myeloma. JAMA Oncol. 2015;1:168-74.

[40] Uggla B, Nilsson TK. Whole blood viscosity in plasma cell dyscrasias. Clin Biochem. 2015;48:122-4.

[41] Van De Donk NWCJ, Mutis T, Poddighe PJ, Lokhorst HM, Zweegman S. Diagnosis, risk stratification and management of monoclonal gammopathy of undetermined significance and smoldering multiple myeloma. Int Jnl Lab Hem. 2016;38(Suppl. 1):110-22.

[42] Vaya A, Suescun M. Hemorheological parameters as independent predictors of venous thromboembolism. Clin Hemorheol Microcirc. 2013;53:131-41.

[43] Wang WQ, Zhao XY, Wang HY, Liang Y. Increased fatty acid synthase as a potential therapeutic target in multiple myeloma. J Zhejiang Univ Sci B. 2008;9:441-7.

[44] Weiss BM, Abadie J, Verma P, Howard RS, Kuehl WM. A monoclonal gammopathy precedes multiple myeloma in most patients. Blood. 2009;113:5418-22.

[45] Za T, De Stefano V, Rossi E, Petrucci MT, Andriani A, Annino L, Cimino G, Caravita T, Pisani F, Ciminello A, Torelli F, Villivà N, Bongarzoni V, Rago A, Betti S, Levi A, Felici S, Gentilini F, Calabrese E, Leone G. for the Multiple Myeloma GIMEMA-Latium Region Working Group. Arterial and venous thrombosis in patients with monoclonal gammopathy of undetermined significance: Incidence and risk factors in a cohort of 1491 patients. Br J Haematol. 2013;160:673-9. 